\title{
SIMULATION STUDY OF ADVANCED VARIABLE DISPLACEMENT ENGINE COUPLED TO POWER-SPLIT HYDRAULIC HYBRID POWERTRAIN
}

\author{
Fernando Tavares, Rajit Johri, and Zoran Filipi* \\ Mechanical Engineering, University of Michigan \\ Ann Arbor, Michigan, USA 48105 \\ Phone: (734) 936-0427 \\ Fax: (734) 764-4256 \\ Email: ftavares@umich.edu, rajit@umich.edu, filipi@umich.edu \\ * Corresponding Author
}

\begin{abstract}
The simulation-based investigation of the variable displacement engine is motivated by a desire to enable unthrottled operation at part load, and hence eliminate pumping losses. The mechanism modeled in this work is derived from a Hefley engine concept. Other salient features of the proposed engine are turbocharging and cylinder deactivation. The cylinder deactivation combined with variable displacement further expands the range of unthrottled operation, while turbocharging increases the power density of the engine and allows downsizing without the loss of performance. While the proposed variable displacement turbocharged engine (VDTCE) concept enables operations in a very wide range, running near idle is impractical. Therefore, the VDTCE is integrated with a hybrid powertrain allowing flexibility in operating the engine, elimination of idling and mitigation of possible issues with engine transients and mode transitions. The engine model is developed in AMESim using physical principles and 1-D gas dynamics. A predictive model of the power-split hydraulic hybrid driveline is created in SIMULINK, thus facilitating integration with the engine. The integrated simulation tool is utilized to address design and control issues, before determining the fuel economy potential of the powertrain comprising a VDTCE engine and a hydraulic hybrid driveline.
\end{abstract}

\section{INTRODUCTION}

Development of modern vehicles is driven by the need to address the energy security and climate change with increased fuel economy, while simultaneously meeting strict exhaust emission regulations. Hybrid technologies are critical for reducing emission and vehicle fuel consumption. This is due to the possibility of (i) downsizing the engine, (ii) recovering energy during regeneration, and (iii) optimizing engine operation. The latter has traditionally been very important for hybrids equipped with an SI engine. Pumping losses (throttled operation) in an SI engine is its Achilles heel and is the main reason for its poor fuel economy at part load. Therefore, hybrid system design and control typically attempts to avoid extended low load operation, thus improving the average fuel conversion efficiency over the driving cycle. Various concepts to reduce pumping loss like variable valve timing and variable cylinder displacement have been proposed over time, therefore offering pathways for further improvement of overall powertrain efficiency. Our intention is to explore the potential of combining one such system for varying engine displacement with a hybrid driveline. In this case the role of hybridization is to enable the application of an advanced engine concept that might be viable only within a certain operating range.

Concept of variable displacement has been addressed in many technical publications over the last few decades, but it has not yet been demonstrated on a production engine. Several authors $[1,2,3]$ have proposed different mechanisms to achieve variable in-cylinder displacement. Pouliot et al. [4], proposed, constructed and studied a 5-cylinder, four-bar linkage engine. Wong et al. [5] presented and analyzed a four cylinder engine with Alvar cycle that utilizes secondary pistons and auxiliary chambers. Independent of the actual means of achieving variable displacement several authors explored the theoretical aspects of applying such a concept. Early work by Siegla and Siewert [6] estimated that the Variable Stroke Engine could improve fuel economy by up to $20 \%$, depending on allowable NOx emissions and vehicle power-to-weight ratio. In a followup experimental study Siewert [7] uncovered penalties associated with combustion deterioration and increased heat losses at very short strokes. Alsterfalk et al. [8] studied the 
potential and limitations of a variable stroke engine with a quasi-dimensional SI engine simulation, and showed that significant efficiency improvements could be obtained within the range of $30 \%$ to $70 \%$ engine load by varying the stroke length and operating unthrottled. Below 30\% load the penalties due to unfavorable changes of combustion chamber proportions with extremely short stroke start to outweigh the benefits of operating unthrottled, while near-idle operation necessitates throttling. This paper attempts to overcome the described challenges by combining a mechanism for varying engine displacement with two other technologies, i.e. the cylinder deactivation and hybridization. The combination of varying displacement and deactivating cylinders moves the lower boundary of unthrottled operation closer to idle, while the power-split hydraulic hybrid system allows avoiding unfeasible operating regions. The engine is also turbocharged to maximize the benefits of downsizing.

A power-split architecture similar to the Toyota hybrid system in a Prius was chosen [9]. However, instead of using electric components, the proposed system is a hydraulic hybrid, comprising of two pump/motors coupled to a planetary gear set and a hydro-pneumatic accumulator for energy storage. The hydraulic components have very high-power density and conversion efficiency, and that makes them very effective in recovering kinetic energy during braking. Another advantage is the relatively low cost when compared to very advanced electrical batteries [10]. However, comparatively low energy density of the hydraulic accumulator creates a special challenge and requires novel approaches to development of the supervisory control. The features of the parallel and series hydraulic hybrid architectures have been investigated before, particularly in the context of heavier vehicles [11, 12, 13], and the optimization of the design and control strategies led to impressive fuel economy improvements. The power-split system has been extensively studied only in the context of hybrid electric vehicles [14], and it demonstrated the ability to marry some of the best features of both the parallel and series systems. Therefore, our aim is two-fold: (i) to investigate whether the power-split HHV enables unthrottled operation of the VDTCE under normal driving conditions, and (ii) to understand challenges related to the development of the supervisory control for a power-split hydraulic hybrid. The constraints in the supervisory control problem are significantly different than in the case of the Hybrid Electric system, due to very different speed ranges of hydraulic energy conversion components and lower capacity for energy storage. Of course, the study ultimately provides an indication of the fuel economy potential offered by the proposed powertrain configuration.

The investigation relies on predictive simulation tools. The two-liter, four-cylinder turbocharged direct injection Variable Displacement Engine is modeled in AMESim ${ }^{\mathrm{TM}}$. The cylinder model considers a thermodynamic control volume and accounts for mass and energy conservation, combustion, and heat transfer. One-dimensional gas dynamics models of manifolds and runners/ports enable coupling of the turbocharger and engine cylinders. Mechanical losses are estimated using a classic empirical correlation based on engine speed, but we do realize that the Hefley engine with its intricate bearing assembly and axially loaded actuator may have somewhat higher losses than the conventional baseline. The hydraulic energy conversion and storage components, and the power-split transmission are modeled based on physical principles in SIMULINK $^{\mathrm{TM}}$, and the same software platform is used for ultimate integration of the powertrain and the vehicle. The basis for integration was the Vehicle Engine SIMulation (VESIM) platform previously developed by the researchers at the University of Michigan Automotive Research Center. Among others, the VESIM has been previously configured for studies of the hydraulic hybrids utilizing a parallel [11] or series architecture [13].

The paper is organized as follows. The VDTCE concept is explained first, as well as the modeling approach. Main features of the engine are illustrated with simulation results, as well as the BSFC improvements at part load. Next, we discuss the configuration of the power-split hydraulic hybrid system and the modeling of the driveline, the hydraulic components and the vehicle dynamics. Efficient supervisory control of different power sources is critical for fully utilizing the potential of hybrid powertrains, therefore the unique challenges associated with the control of the PS-HHV system are explored in a separate sub-section. A modulated control of the accumulator State-of-Charge is proposed, together with the positioning of the engine operating points on the optimal BSFC trajectory. Finally, the proposed powertrain configuration comprising the VDTCE engine and a power-split hydraulic hybrid is simulated over the EPA Urban and Highway Driving Cycle, and compared with a baseline vehicle equipped with a conventional SI engine and a 5-speed automatic gear box. The paper ends with conclusions.

\section{VDTCE CONCEPT AND MODELING}

A variable displacement engine concept allows the cylinder swept volume to change based on actuation command. The change in the chamber size is realized by moving the piston top dead center (TDC) and the bottom dead center (BDC) positions. The main idea is to enable modulation of engine output by changing the displacement rather than throttling the intake air. Operating the engine at wide open throttle (WOT) eliminates excessive pumping losses at part load, and hence significantly increases the part-load efficiency.

The variable displacement engine concept chosen for this study is based on the Hefley design [15]. Figure 1 shows a schematic of the mechanism proposed by the inventor. The Hefley engine orients the engine cylinders radially around the shaft, but at an angle with respect to the crank rotation plane. This allows the pistons to be connected to a single "crankshaft" with a special bearing assembly capable of moving along the axis of an inclined "crank". The spherical joints act as the 
connecting rod big ends and allow reciprocating motion of the piston for different positions of the bearing assembly. If a different displacement is needed, the bearing assembly is moved up or down the crank to change the engine stroke. Our study investigates the potential for improving the engine cycle efficiency with such a concept, and attempts to understand the operating limits and possible powertrain integration challenges. Therefore, the kinematics and geometric constraints of such a mechanism are viewed as a realistic platform, while it is not our intention to address the details of component design, and reliability or cost of such an engine.

The practical considerations and constraints of the Hefley concepts are as follows. The engine compression ratio can either be kept constant or allowed to vary over a small range. The compression ratio is kept constant in this work due to knock considerations. The minimum engine displacement is limited due to the geometric constraints and it determines the lower boundary of the engine power band. The preliminary analysis has shown that the low power limit is still far away from idle when operating the VDTCE unthrottled, since the realistic range for varying displacement is roughly $2: 1$. To further extend the unthrottled operation downward deactivation is considered as well. On the upper end, the power band is extended with turbocharging. Therefore, the 2-liter VDTCE engine is intended to replace the $3.6 \mathrm{~L}$ conventional naturally aspirated baseline. Table 1 contains main engine specifications.

Modeling of the engine thermodynamic and gas dynamic processes is pursued using LMS Imagine.Lab AMESim ${ }^{\mathrm{TM}}$ multidomain software platform. This platform allows integration of individual modules in a graphical programming environment (see Figure 2), facilitates implementation of the controller and provides a SIMULINK interface if so required. The next section provides details of the modeling approach and illustrates the VDTCE behavior.

Table 1: Engine Specifications

\begin{tabular}{lcc}
\hline Displacement & $1-2$ & $(\mathrm{~L})$ \\
Bore & 83 & $(\mathrm{~mm})$ \\
Stroke & $41.5-83$ & $(\mathrm{~mm})$ \\
Connecting Rod Length & 160 & $(\mathrm{~mm})$ \\
Compression Ratio & 10.2 & \\
Number of Cyl. & 4 & \\
Valves per Cyl. & 4 & \\
\hline
\end{tabular}

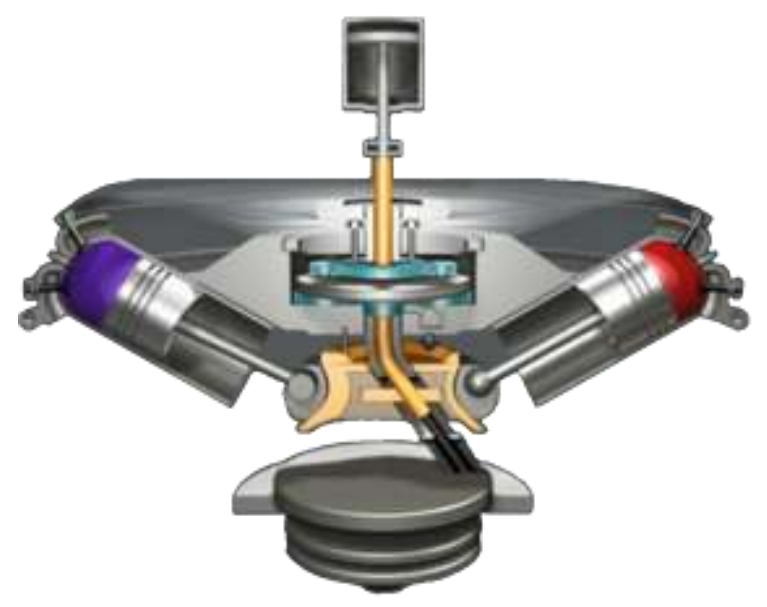

Figure 1: Hefley Engine Concept [15]

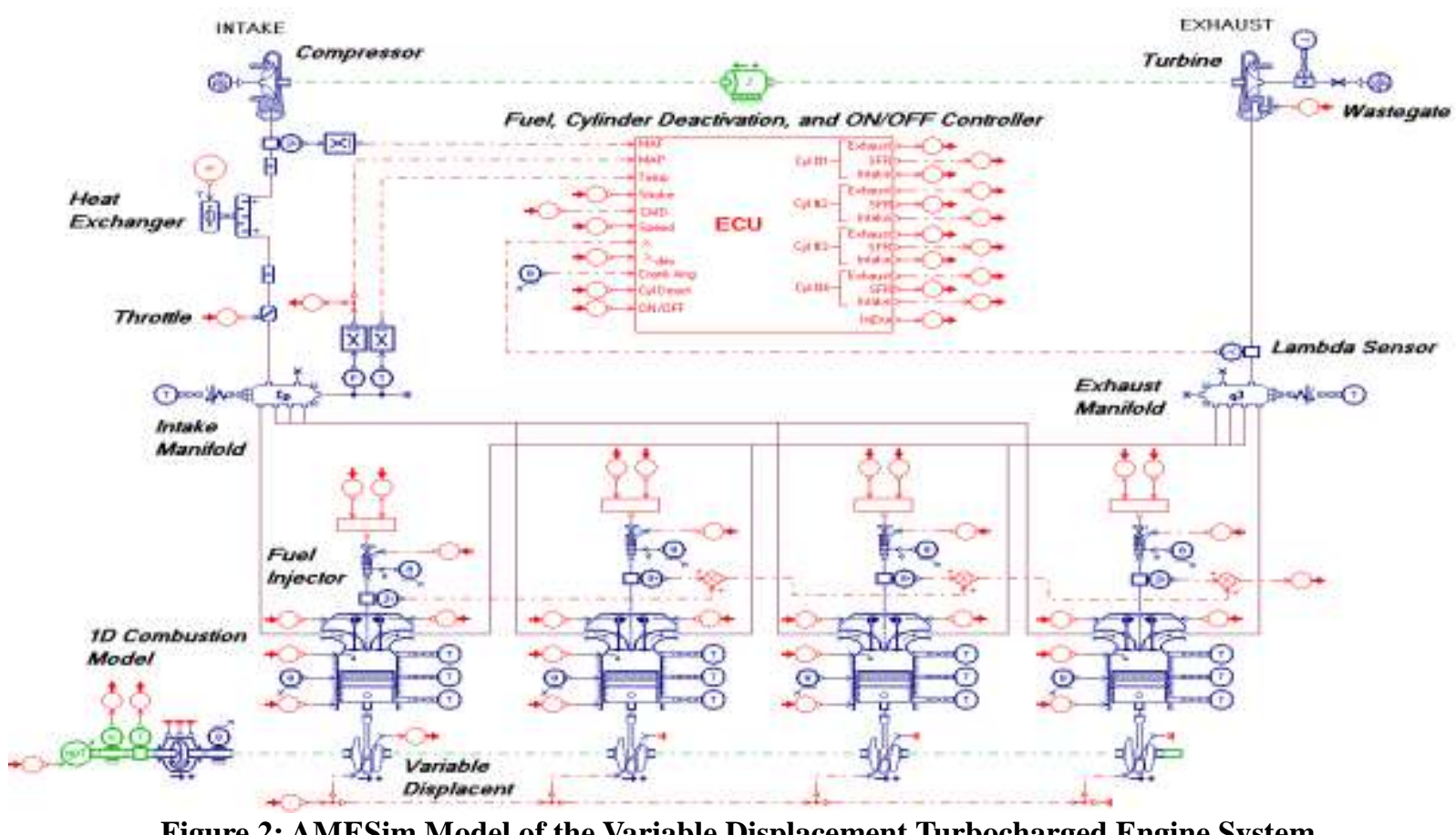

Figure 2: AMESim Model of the Variable Displacement Turbocharged Engine System 


\section{Engine Cylinder Model}

A phenomenological combustion model from AMESim [16] was a basis for developing a VDTCE cylinder module. The model considers a thermodynamic control volume and accounts for mass and energy conservation, combustion, and heat transfer. The calculation of the instantaneous cylinder volume had to be modified to allow dynamic changes of the engine displacement, details of which will be presented in a separate sub-section. The contents of the cylinder are a mixture of three gases, namely air, fuel vapor, and burned gas. The fuel is defined by the number of carbon and hydrogen atoms $\left(\mathrm{C}_{\mathrm{x}} \mathrm{H}_{\mathrm{y}}\right)$ and its lower heating value. The fuel is injected as a liquid, and its evaporation affects the thermodynamic state of the charge in the cylinder. Evaporation of the fuel is modeled as an evaporation time constant dependent on the mixture temperature. The heat transfer between the gas and combustion chamber walls is calculated using the Woschni model.

The combustion model considers the composition of two zones, in which different species are separated by the flame into unburned and burned gas zone. The reaction rate is computed using a coherent flame model, which requires information about the laminar flame speed and total flame surface. The laminar speed is determined from the Metghalchi and Keck correlation [17] based on the instantaneous temperature and pressure of the unburned gases. The total flame area is a combination of the mean flame surface and the flame front wrinkling. The mean flame area is calculated assuming propagation of a spherical front with the center at the spark plug until a contact with the piston. After the flame touches the piston the analysis is simplified by assuming the cylindrical shape of the flame. The flame front wrinkling is based on Damköhler's analytical expression [18], which considers the turbulence effect on the flame wrinkling. A zero-dimensional energy cascade model calculates the turbulent kinetic energy.

Predicting knock is critical for determining the realistic boosting limit. It is achieved by computing the evolution of precursor specie [19]. When the ratio between the mass fraction of the precursor specie and the initial fuel mass fraction reaches one, the induction time has elapsed and the autoignition occurs. A simple algebraic model developed at the Institute Francais du Petrole provides estimates of the knock intensity [19].

\section{Crankshaft Model for a Variable Displacement Engine}

A new crankshaft model was created to allow the engine displacement to vary based on the bearing assembly actuator position. The Hefley engine concept shown in Figure 1 is replicated by modifying the standard crankshaft model to enable variations of the crank radius and the relative position of the crank journal. The model also includes a delay to represent the first order dynamics of the actuator used to move the crank bearing assembly. The model was implemented in AMESim as
$\mathrm{C}$ code and its predictions are illustrated in Figure 3. The figure shows the variation of the cylinder volume from maximum to minimum after a step change of actuator command. To keep the compression ratio constant the ratio between the minimum and maximum volume is kept constant. This is possible by changing the clearance height proportionally to the stroke length.

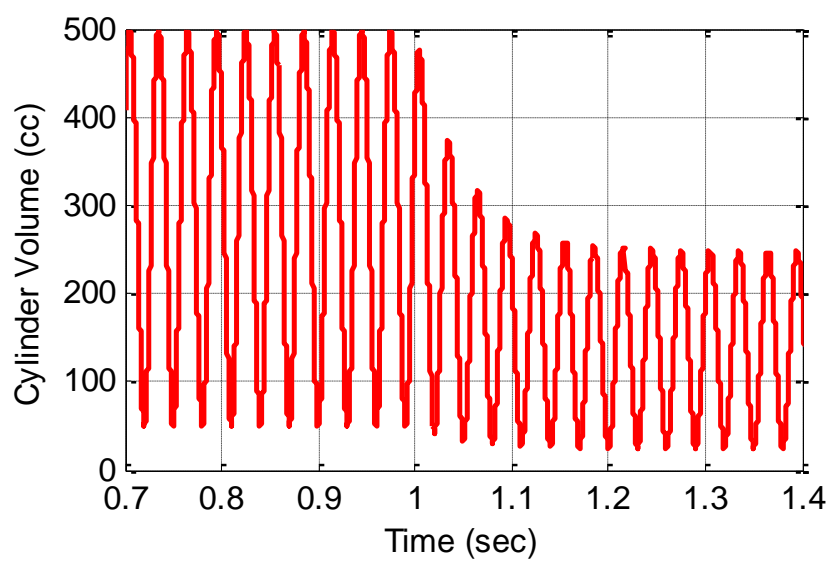

Figure 3: Cylinder volume $\left(\mathrm{cm}^{3}\right)$ history after a command change from "full" to "minimum".

\section{Intake and Exhaust Systems}

The intake and exhaust systems are constructed by linking manifolds with pipes and implementing one-dimensional gas dynamic models. This enables predictions of the wave action in manifolds and runners and provides accurate predictions of engine breathing.

\section{Turbocharger}

The turbocharger model contains three components: compressor, turbine, and rotor dynamics. The compressor and turbine models are from the AMESim Library [20], [21] and are lookup table based. The mass flow rate through the waste gate is computed using the compressible flow equation with variable throat area. The turbine size was optimized to achieve high boost pressure at low speeds. A wastegate is implemented to prevent overboosting at high engine speeds. The waste gate command is calculated based on engine speed, desired boost pressure, and actual boost pressure. A block diagram of the wastegate controller is shown in Figure 4.

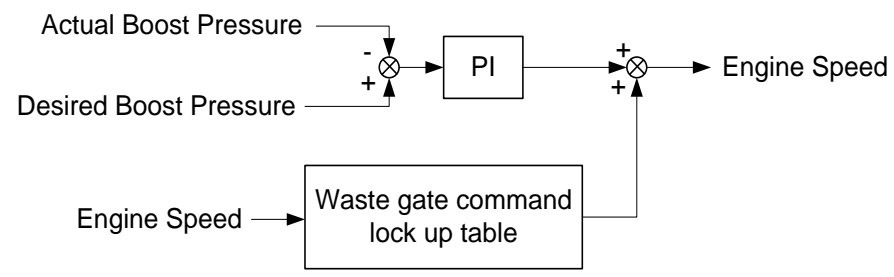

Figure 4: Waste Gate Control with Feedforward and Feedback 
In order to calculate the maximum desired boost pressure, the knock intensity values were analyzed at different engine speeds. In doing this it was possible to create a look up table for feedforward wastegate control. Figure 5 and Figure 6 illustrate a test scenario for engine speed of 3000 RPM. Boost pressure was allowed to build up gradually, as shown in Figure 5.

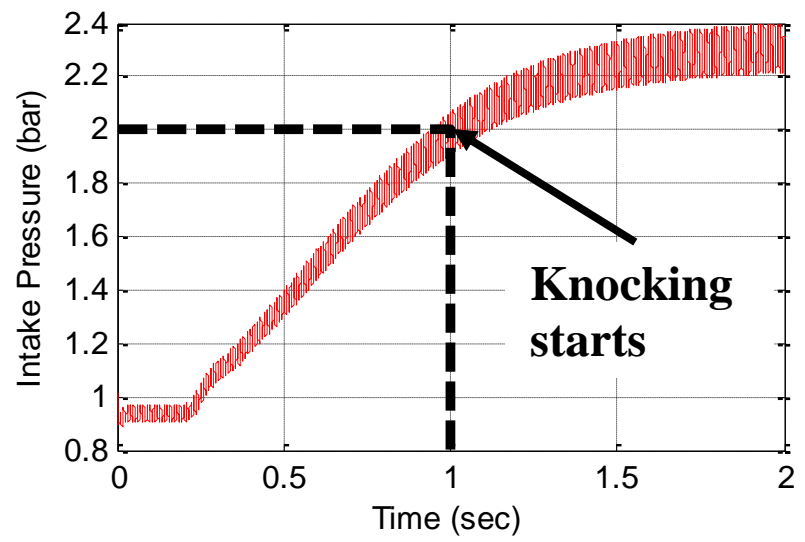

Figure 5: Intake pressure build up from "zero" boost. Engine condition: 3000 RPM and $50 \%$ displacement

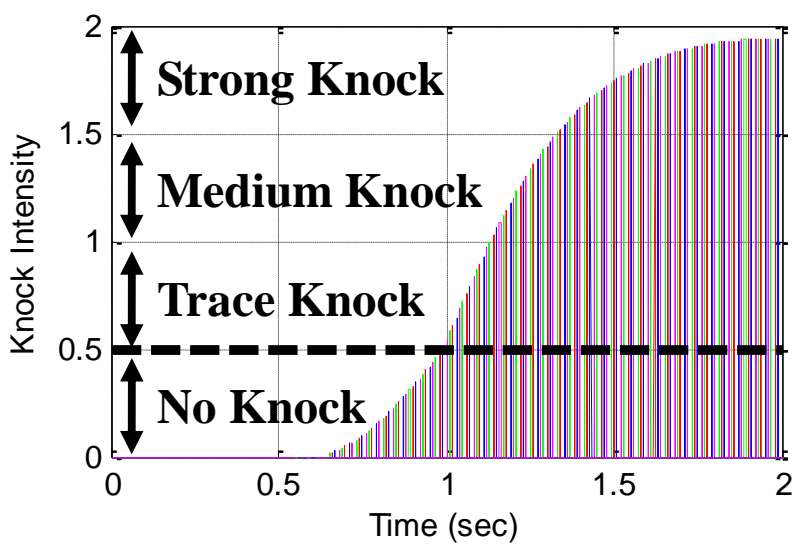

Figure 6: Knock intensity variation for boost pressure history shown in Figure 5.

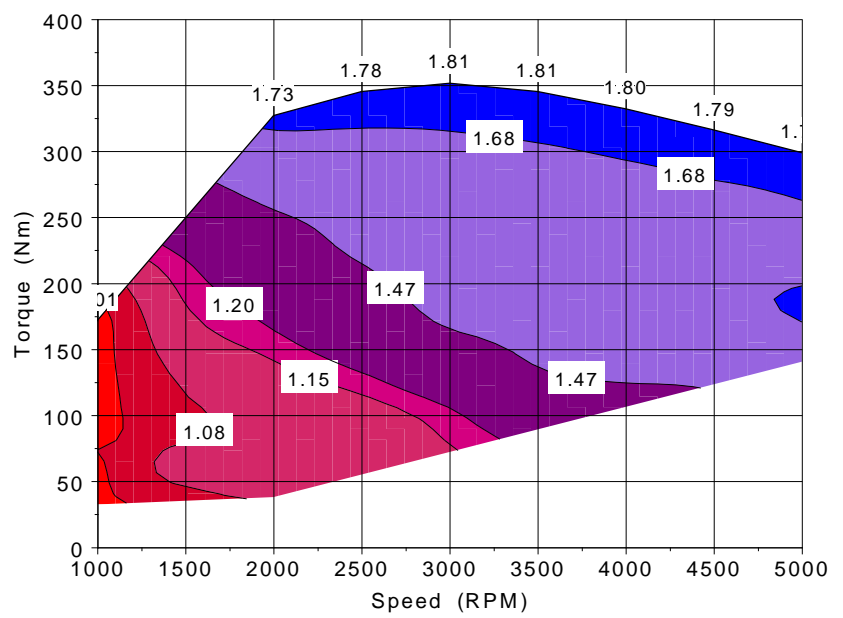

Figure 7: Intake manifold pressure Map (bar)
The knocking intensity was tracked throughout the transient, and knocking occurred roughly 1 second into the transient (see Figure 6). This corresponds to $\sim 2$ bars of boost, and a safer value of 1.8 was chosen as the practical boost limit. Similar simulations for different engine speeds allowed us to generate the boost pressure map (see Figure 7) for the VDTCE engine.

\section{Fuel Controller}

The engine fuel controller used for the VDTCE is a modified implementation of a concept patented by Mladenovic (GM) [22]. The air flow rate is estimated based on the manifold gas pressure, temperature and mass air flow rate through the throttle. The modification of the original methodology allows calculating the effect of the variable cylinder volume.

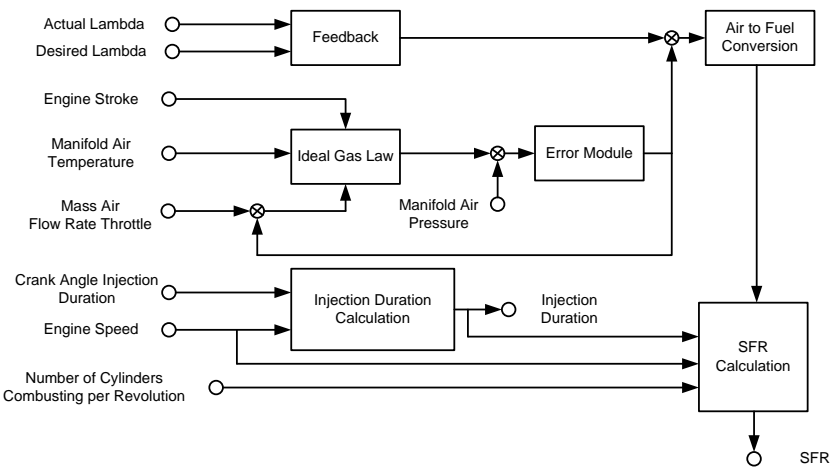

Figure 8: Fuel controller block diagram

Hence, the feedforward portion of the fuel controller relies on signals for the mass air flow past the throttle, temperature and piston stroke to calculate estimated manifold pressure. This estimated pressure is then compared with the actual manifold pressure signal to create an error value. The error module then estimates the cylinder air flow rate using a PI controller, and this in turn allows computing the desired amount of fuel injected. The fine adjustments are achieved by adding the feedback loop for the normalized air-to-fuel ratio (Lambda). The estimated fuel injection rate, injection duration, engine speed, and number of combustion events per revolution are used to calculate the overall static fueling rate (SFR).

$$
\begin{gathered}
\dot{m}_{f b}=K_{p, f b} \cdot\left(\lambda-\lambda_{d e s}\right)+K_{i, f b} \int\left(\lambda-\lambda_{d e s}\right) \cdot d t \\
V_{c y l}=L \cdot d_{p}^{2} / 4 \\
d P_{c} / d t=\dot{m}_{t}-\dot{m}_{f f} / V_{c y l} \cdot R \cdot T \\
\dot{m}_{f f}=K_{p, f f} \cdot\left(P_{e}-P_{a}\right)+K_{i, f f} \int\left(P_{e}-P_{a}\right) \cdot d t \\
\dot{f}=\left(\dot{m}_{f f}+\dot{m}_{f b}\right) / A F R \\
t_{i n j}=\boldsymbol{O}_{i d} \cdot \omega \\
S F R=\dot{f} /\left(\omega \cdot N \cdot t_{i n j}\right)
\end{gathered}
$$




\section{Cylinder Deactivation}

The cylinder deactivation was implemented to allow unthrottled engine operation at very small loads. Cylinder deactivation turns off 2 cylinders and thus further reduces the engine displacement by half. Cylinder deactivation logic deactivates a cylinder during its exhaust stroke. The next cylinder to be deactivated is its pair cylinder. Pairs are cylinders 1 and 4 or cylinders 2 and 3 . When cylinders are deactivated their intake and exhaust valves are kept closed to preserve high in-cylinder temperatures, and prevent oxygen rich exhaust from flowing past the oxygen sensor and into the catalytic converter. Figure 9 shows the mean engine torque value of the VDTCE during a cylinder deactivation period. The undershoot is noticed immediately after deactivation due to relative increase of mechanical losses, and the controller quickly corrects this by adjusting the stroke of a Hefley engine.

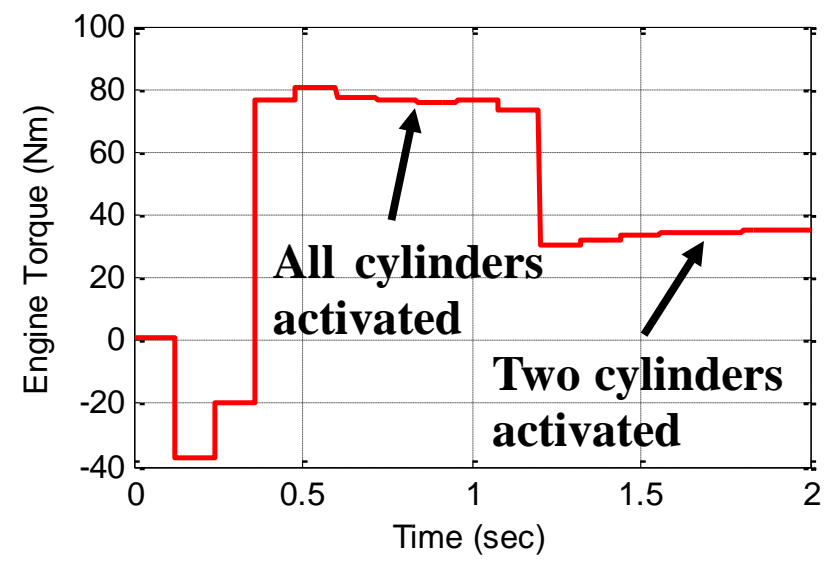

Figure 9: Cylinder deactivation - avg. engine torque (Nm)

\section{Friction Model}

The friction model is an empirical relation based on engine speed and same expression was used for both the VDTCE engine and conventional baseline engine.

$$
F M E P=0.97+0.15 \cdot N / 1000+0.05 \cdot(N / 1000)^{2}
$$

We realize that mechanical losses of a Hefley engine with an intricate bearing assembly and heavy axial loads on the main actuator may be different than those observed in a conventional engine, but there are no published data quantifying the rubbing friction in a Hefley engine. Therefore, applying the same FMEP correlation was deemed "safer" than attempting to make estimates without any guidance from actual measurements. The caveat stated above means that we need to view the brake specific fuel consumption (BSFC) values presented in the next section with caution, as the overall efficiency levels of the VDTCE may be somewhat overpredicted.

\section{VDTCE Implementation}

This section discusses interaction in the system and the control logic for various modes of operation. In the VDTCE engine the power can be controlled in the following ways: $1-$ variable displacement command, 2 - cylinder deactivation command, 3 - turbine wastegate command, 4 - spark timing. The variable displacement command is the main method of power regulation. If further power reduction beyond the level obtained with minimum displacement command at WOT is necessary cylinder deactivation is used. The smooth mode transition is enabled by a simultaneous fine adjustment of cylinder displacement during deactivation. As explained in the section on turbocharging, the turbine wastegate command is generated based on a pre-determined look up table which defines the maximum boost pressure attainable without the occurrence of knock. Given that the VDTCE operates at WOT at all times, the spark advance is effectively limited by the knock and is retarded compared to the typical values seen in conventional engines.

After successfully building the engine system simulation already shown in Figure 2, several runs were made to generate a BSFC map shown in Figure 10. The peak torque is determined by the maximum displacement and allowable boost levels. High- and mid-load regions are controlled via a variable displacement actuator. The bottom part of the map and the actual low-load limit are the result of combining cylinder deactivation and variable displacement. It can be seen that the combination of technologies enables highly efficient operation throughout the operating range. The minimum BSFC values are around $190 \mathrm{~g} / \mathrm{kW}-\mathrm{hr}$ and the maximum are on the order of 310 $\mathrm{g} / \mathrm{kW}$-hr, which is perhaps two times better than typical lowload values observed in conventional SI engines. The map does cover the entire range, i.e. a very bottom of the load range and near-idle operation is not attainable unless we start throttling the intake. As explained in our objectives, we plan to avoid that by coupling the engine with the hybrid system and using the control authority to keep the engine operating above the low-load limit at all times.

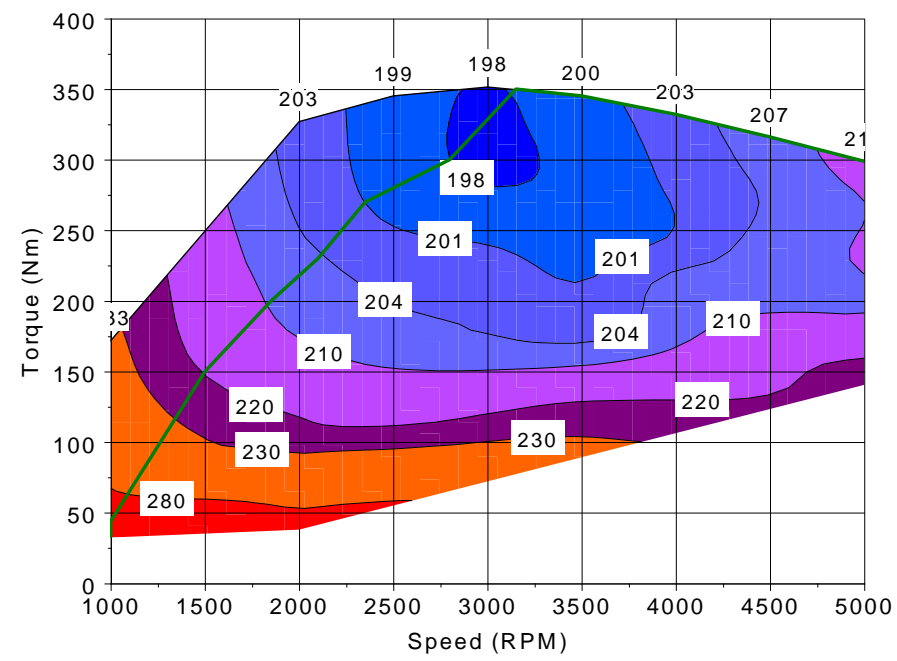

Figure 10: Break Specific Fuel Consumption map of the VDTC engine and best BSFC trajectory 


\section{HYDRAULIC HYBRID POWER-SPLIT PROPULSION SYSTEM}

A hybrid powertrain is a device that allows an extra degree of freedom by adding an energy storage device and a secondary propulsion device. This provides more flexibility in controlling the engine. In addition, a reversible motor in the driveline enables regeneration of braking energy and fuel economy gains in urban driving. A power-split hybrid architecture is selected for this work in order to utilize the best features of both the parallel and series hybrid architectures. The driveline component models were developed in SIMULINK and integrated using the Vehicle Engine SIMulation (VESIM) framework developed by the researchers of the Automotive Research Center at the University of Michigan [11-13]. Table 2 gives an overview of the vehicle system specifications.

Table 2: Vehicle Specifications

\begin{tabular}{|c|c|c|}
\hline Engine & $\begin{array}{l}\text { Description } \\
\text { Max. Power } \\
\text { Max. Torque }\end{array}$ & $\begin{array}{l}\text { 2L VDTCE } \\
156 \mathrm{~kW} @ 5000 \mathrm{RPM} \\
350 \mathrm{Nm} @ 3000 \mathrm{RPM}\end{array}$ \\
\hline $\begin{array}{l}\text { Motor / } \\
\text { Pump }\end{array}$ & Design & $\begin{array}{l}\text { Axial Piston Variable } \\
\text { Displacement }\end{array}$ \\
\hline & $\begin{array}{l}\text { Size } \\
\text { Max Speed }\end{array}$ & $\begin{array}{l}110 \mathrm{cc} / \mathrm{rev} \\
4000 \mathrm{RPM}\end{array}$ \\
\hline Accumulator & $\begin{array}{l}\text { Type } \\
\text { Gas } \\
\text { Capacity (Max. Gas } \\
\text { Volume) } \\
\text { Max Pressure } \\
\text { Min Pressure }\end{array}$ & $\begin{array}{l}\text { Gas Charged } \\
\text { Nitrogen }\left(\mathrm{N}_{2}\right) \\
35 \text { Liter } \\
350 \text { bar } \\
120 \text { bar }\end{array}$ \\
\hline Vehicle & $\begin{array}{l}\text { Type } \\
\text { Weight } \\
\text { Coefficient of Drag } \\
\text { Frontal Area } \\
\text { Tire Radius } \\
\text { Final Drive Ratio }\end{array}$ & $\begin{array}{l}\text { Sedan } \\
1535 \mathrm{~kg} \\
0.27 \\
2 \mathrm{~m}^{2} \\
0.327 \mathrm{~m} \\
3.38\end{array}$ \\
\hline $\begin{array}{l}\text { Planetary } \\
\text { Gear Drive }\end{array}$ & $\begin{array}{l}\text { Design } \\
\text { Ratio (Ring / Sun) } \\
\text { Speed Reducer Ratio }\end{array}$ & $\begin{array}{l}\text { Modified THS } \\
2.6: 1 \\
3: 1\end{array}$ \\
\hline
\end{tabular}

\section{Power-split system}

The heart of the power-split system is a planetary gear drive that integrates two energy converters, in this case hydraulic pump/motors. It utilizes the so called speeder-torquer logic to control the engine operation while providing desired torque at the wheels. The system combines best features of parallel and series architectures, namely a great flexibility in controlling the engine, effective regeneration via the "torquer" and mechanical transmission of power from the engine to the wheels in certain modes of operation, thus avoiding losses associated with multiple energy conversions. Figure 11 shows the power-split configuration schematic and a lever diagram analogy illustrating the speed and torque relationships in the power-split device.

A basis for development of the power-split system was the Toyota Hybrid Electric System (THS) [9]. Similarly to THS, the vehicle and motor are connected to the ring gear and the engine to the carrier gear. However, the pump is connected to the sun gear through a speed reducer (see Fig. 11), due to a much lower max allowable rotational speed of the hydraulic motor. The generator in the original THS concept experiences very high speeds, above $10,000 \mathrm{rpm}$, while the hydraulic pump speed should not exceed $4000 \mathrm{rpm}$. The following equations show the relationship between the component torques and speeds:

$$
\begin{gathered}
T_{c}=-(R+S) \cdot T_{v} / R \\
T_{r}=R / S \cdot T_{v} \\
\omega_{c}=\omega_{e}=\int\left(T_{e}-T_{c}\right) / I_{e} \cdot d t \\
\omega_{r}=v / R_{\text {tire }} \cdot F R \\
\left.\omega_{v}=\omega_{s} / S R=\left(\omega_{c} \cdot(R+S)-\omega_{r} \cdot R\right) / S \cdot S R\right)
\end{gathered}
$$
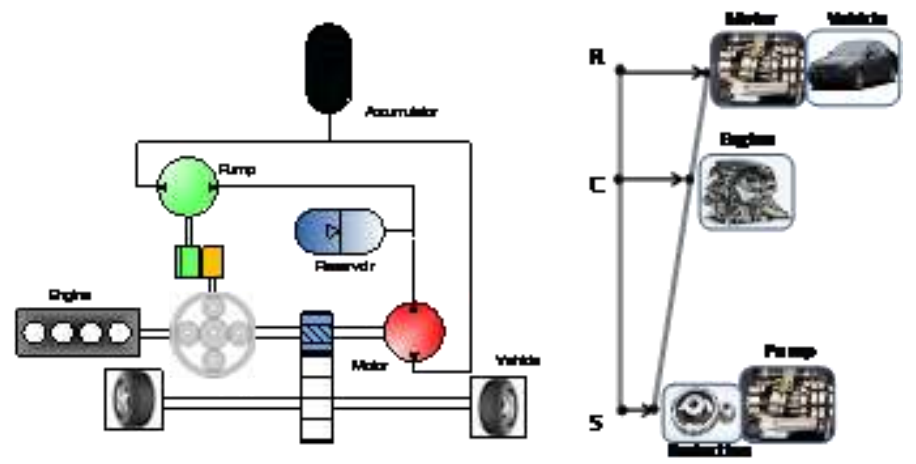

Figure 11: Modified power-split architecture with Hydraulic Components, and a lever diagram of the proposed PS-HHV system.

\section{Driver}

The driver was modeled as a proportional integral controller acting on the error between the actual vehicle velocity and the desired vehicle velocity defined by the selected driving schedule:

$$
c o m_{d r}=K_{p, d r} \cdot\left(v_{d e s}-v_{a c t}\right)+K_{i, d r} \int\left(v_{d e s}-v_{a c t}\right) \cdot d t
$$

\section{Engine}

The engine was developed in AMESim, and its details were given in earlier sections. For a system integration study in SIMULINK, the predictive AMESim model was used to generate a look-up table yielding torque as a function of engine speed and mass of injected fuel. The cascading from the predictive AMESim model to the look-up table enables 
addressing all design and control issues with appropriate level of fidelity in the pre-processor, and then capturing the features of the selected design with a compact and fast module. A first order lag was added to simulate the turbocharger delay. A detailed idle controller was designed for conditions when the engine command is zero.

\section{Vehicle}

The vehicle is a point mass based model. This is deemed sufficient for the fuel economy studies. The resistive forces were modeled as rolling and drag resistance. The vehicle also contains a brake model, which acts as a coulombic friction device. The vehicle model equations are given below.

$$
\begin{aligned}
& T_{\text {rollres }}=f \cdot m \cdot g \cdot R_{\text {tire }} \\
& T_{\text {drag }}=0.5 \cdot A_{f} \cdot C_{d} \cdot \rho \cdot \omega_{w}^{2} \cdot R_{\text {tire }}^{3} \\
& T_{\text {brake }}=\left(R_{\text {vis }} \cdot \omega_{w}+\operatorname{sgn}\left(\omega_{w}\right) \cdot F_{\text {stat }}\right) \cdot x_{\text {brake }} \quad \text { if } \omega_{w}>\omega_{\min } \\
& T_{\text {brake }}=\left(R_{\text {vis }} \cdot \omega_{w}+\operatorname{sgn}\left(\omega_{w}\right) \cdot F_{\text {stat }} \cdot \omega_{w} / \omega_{\min }\right) \cdot x_{\text {brake }} \quad \text { if } \omega_{w}<\omega_{\min } \\
& v=\int\left(T_{\text {drive }}-T_{\text {drag }}-T_{\text {rollres }}-T_{\text {brake }}\right) /\left(m \cdot R_{\text {tire }}\right) \cdot d t
\end{aligned}
$$

\section{Accumulator Model}

A bladder accumulator containing nitrogen and foam was used as the energy storage device. The equations of state for nitrogen, shown below, were obtained from [23], [24], [25] based on the BWR equation for real gas and the conservation of energy:

$$
\begin{gathered}
{\left[\tau+\frac{m_{f} \cdot c_{f}}{h \cdot A_{w}}\right] \cdot \frac{d T}{d t}+T=T_{w}-\frac{T_{\tau}}{c_{v}} \cdot\left[\frac{\partial p_{g}}{\partial T}\right]_{v} \cdot \frac{d v}{d t}} \\
\tau \equiv \frac{m_{g} \cdot c_{v}}{h \cdot A_{w}} \\
p_{g}=\frac{R T}{v}+\frac{B_{0} R T-A_{0}-\frac{C_{0}}{T^{2}}}{v^{2}}+\frac{b \cdot R \cdot T-a}{v^{3}}+\frac{a \cdot \alpha}{v^{6}}+\frac{C\left(1+\frac{\gamma}{v^{2}}\right) e^{-\gamma / v^{2}}}{v^{3} \cdot T^{2}}
\end{gathered}
$$

In equations 20-21, the subscript "g" denotes variables pertaining to gas, and " $\mathrm{f}$ " the corresponding variables, such as mass or specific heat, for the foam. The addition of elastomeric foam increases the heat capacity of the charge and significantly improves the efficiency of the charging-discharging process.

\section{Pump/Motor Model}

The hydraulic pump/motor (P/M) model is an updated version of Wilson's pump/motor theory [23]. The P/M is an axial piston variable displacement type. The torque and flow is controlled by the displacement command. The volumetric and mechanical efficiency equations are shown below.

$$
\begin{aligned}
& \eta_{v, \text { pump }}=Q_{a} / Q_{i}=1-C_{s} /(x \cdot S)-\Delta p / \beta-C_{s t} /(x \cdot \sigma) \\
& \eta_{t, \text { pump }}=T_{i} / T_{a}=1 /\left(1+C_{v} \cdot S / x+C_{f} / x+C_{h} \cdot x^{2} \cdot \sigma^{2}\right)
\end{aligned}
$$

Consequently, the actual instantaneous torque or flow are calculated by multiplying theoretical values corresponding to the instantaneous displacement and speed with the efficiencies determined from equations 23-24.

\section{INTEGRATION AND SUPERVISORY CONTROL}

Maximizing the benefits of hybridization critically depends on the supervisory control strategy tailored specifically for a selected configuration and component design. In case of the hydraulic hybrid, the relatively low energy density of the energy storage device requires careful management of the State-of-Charge (SOC), and development of the strategy that guarantees maintaining the $\mathrm{SOC}_{\min }$, while optimizing the overall performance and efficiency of the power-split hybrid system. A modulated control strategy proposed by Filipi and Kim [26] produced excellent results when applied to the series hydraulic hybrid system, and therefore was selected as the basis for developing a controller for the PS-HHV.

Modulated control determines the engine command based on the deviation of the instantaneous SOC from the desired value, and the rate of change of the difference between the $\mathrm{SOC}_{\mathrm{dem}}$ and actual SOC, i.e.:

$$
P_{e, d}=K_{p} \cdot\left(S O C_{d e m}-S O C\right)+K_{i} \int\left(S O C d_{d e m}-S O C\right) \cdot d t
$$

The desired SOC is low (0.2) in order to provide enough storage capacity for the subsequent regeneration event [13]. In contrast to the traditional thermostatic SOC control, the modulated controller avoids harsh transients and ramps up engine power relatively smoothly, as shown in Figure 12. Based on the controller signal for the engine power demand, the actual desired torque and speed are determined from the intersection of the constant power line and the optimal BSFC trajectory shown in Fig. 10. This is discussed in detail in the next section.

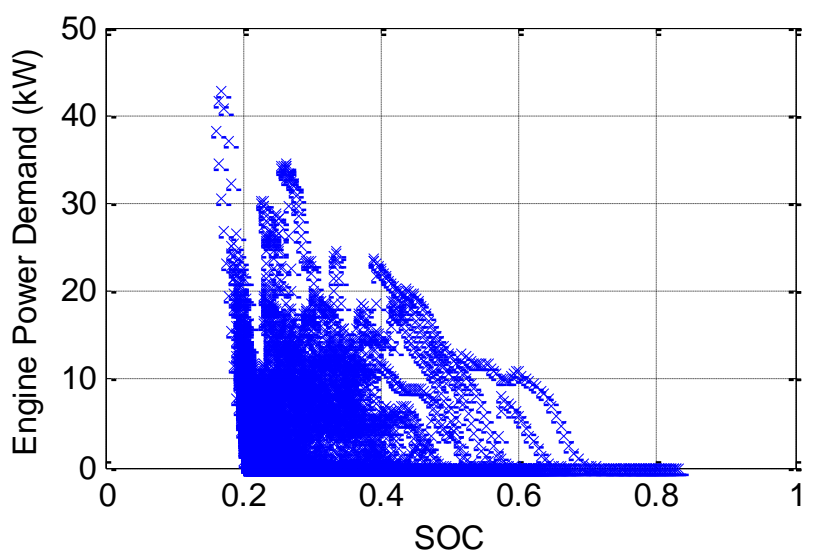

Figure 12 : Engine power demand vs. State-of-Charge predicted over the FTP75 driving schedule 


\section{SIMULATION RESULTS}

The PS-HHV behavior and its fuel economy were assessed over the FTP 75 urban driving cycle. Figure 13 shows results pertaining to a segment of the driving schedule, namely: vehicle speed, engine speed and power histories, power-at-thewheel histories, SOC history, and finally power histories for both hydraulic machines (pump and the motor). The motor speed is obviously directly related to the desired vehicle speed, while the pump rotation reverses, as indicated by the negative RPM values, in order to keep engine at the desired operating point.
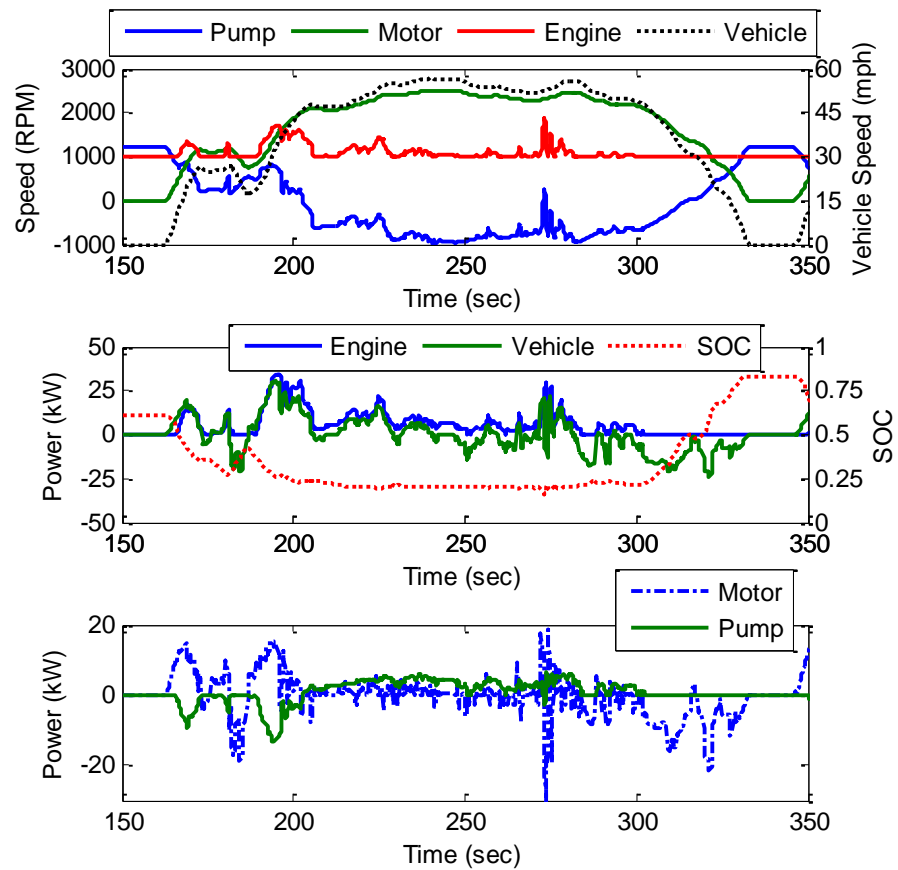

Figure 13: Power-split HHV results over a segment of the FTP 75 driving schedule: vehicle and powertrain component speed histories (top), engine and wheel speed histories, SOC (middle), and pump and motor power histories (bottom).

The middle plot in Fig. 13 indicates that, unlike in the case of the THS electric system, the engine power remains relatively close to the total power requirement throughout most of this segment. The engine provides most of the power requirement, and the controller maintains the SOC limit close to the desired value. However, this does not mean that the engine operates inefficiently. Quite to the contrary, Figure 14 shows that the engine operating points are all grouped around the optimal BSFC trajectory, thanks to the flexibility in controlling the engine provided by the hybrid system. The relative engine load is very low, but the features of the VDTCE remove the penalty associated with the part-load operation of the conventional engine and lead to favorable mean BSFC. Nevertheless, the concentration of operating points in the lower-left quadrant indicates that the engine is sized generously, and that there is significant margin for further downsizing. The desired rated power in this study was selected to match the high-performance conventional vehicle, and this could be changed in future studies. The torque at the wheels occasionally drops into the negative territory, indicating a braking event.

The bottom plot in Fig. 13 illustrates the behavior of hydraulic pump/motors. The pump power resembles the profile of the engine power, but obviously not entirely so, as some of the engine power is transmitted directly to the wheels. Whenever the power command at the wheels is negative, the motor is operated in the pump mode to fulfill the braking requirement and enable regeneration.

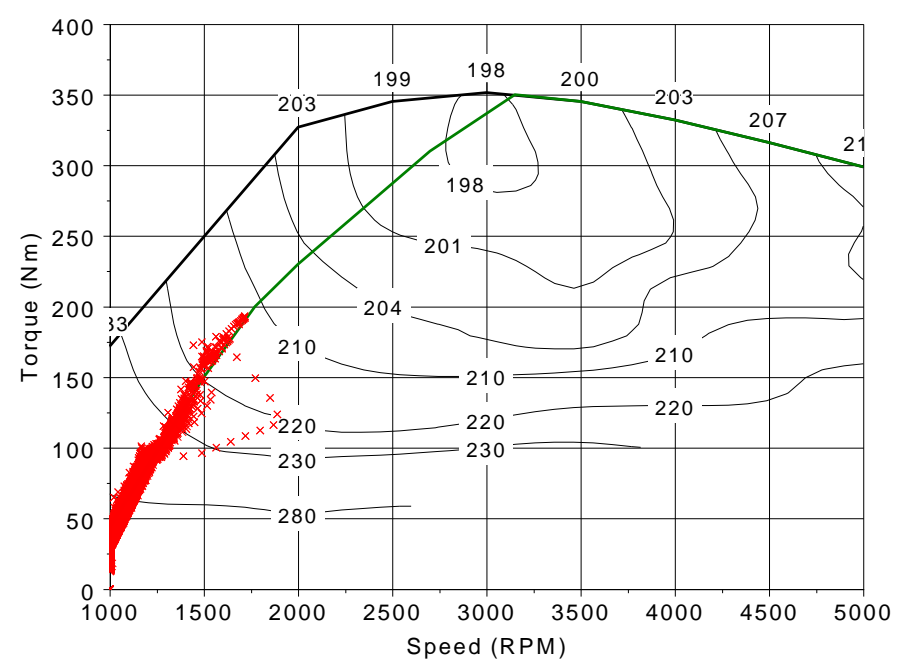

Figure 14: Powersplit vehicle engine operating points for an FTP75 driving cycle

\section{ESTABLISHING A BASELINE FOR COMPARISONS}

To understand the improvements of a vehicle with a VDTCE coupled with a power-split hydraulic hybrid driveline it was necessary to create a model representing a conventional vehicle. Our target platform is a mid-size high-performance passenger vehicle. With this approach we aim to highlight possibility of preserving the high-performance while significantly reducing the fuel consumption, rather than to explore the ultimate fuel economy limit. However, the general observations are applicable to other similar configurations, and the guidance offered by the current study will be valid for future investigations of super-efficient vehicles. In summary, a representative baseline is characterized by setting up a simulation of a $3.6 \mathrm{~L}$ V6 naturally aspirated engine in AMESim, as shown in Figure 15. The engine specifications are summarized in Table 3. The rated power matches the maximum power generated by the VDTCE 2.0 L @ 5000RPM. The throttle and spark timing commands are optimized to generate the BSFC map shown in Figure 16. The engine is mated to a five speed automatic transmission in SIMULINK to create a conventional vehicle system. 


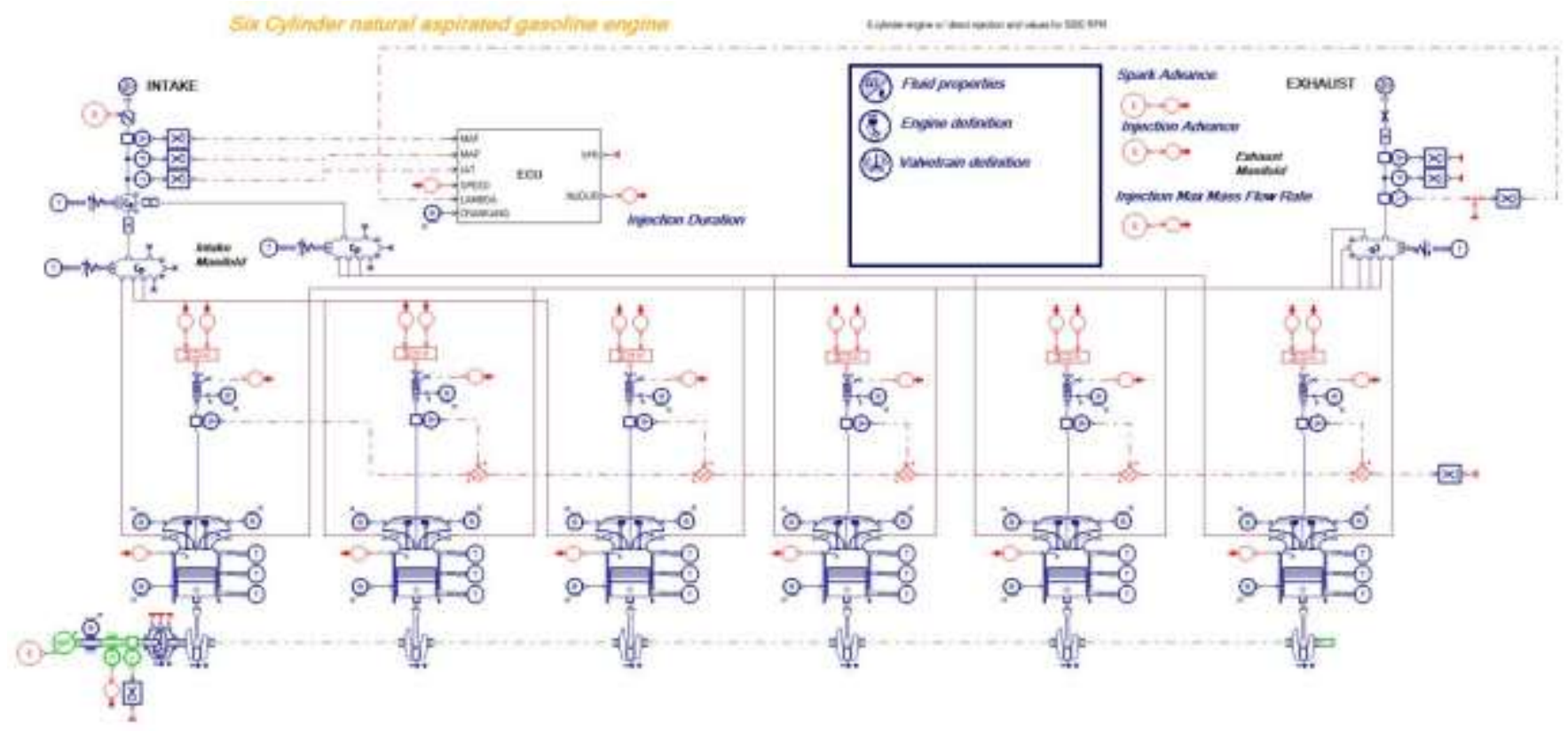

Figure 15: AMESim model of the 3.6 L V6 Engine

Table 3: Baseline Engine Specifications

\begin{tabular}{lcc}
\hline Displacement & 3.6 & $(\mathrm{~L})$ \\
Bore & 94 & $(\mathrm{~mm})$ \\
Stroke & 85.6 & $(\mathrm{~mm})$ \\
Compression Ratio & 11 & \\
Number of Cyl. & 6 & \\
Valves per Cyl. & 4 & \\
\hline
\end{tabular}

\section{Conventional versus Power-split HHV: System Interactions and Fuel Economy}

The 3.6 L V6 engine operating points are superimposed on the BSFC map shown in Figure 16. Clearly, the interactions of the engine with a conventional 5-speed driveline scatter the load/speed points over a wide range, but often keep the engine in the unfavorable mid-speed and low-load area. When the torque requirement is around $50 \mathrm{~N}-\mathrm{m}$, the engine runs with BSFC $>550 \mathrm{~g} / \mathrm{kW}-\mathrm{h}$, rather than $\sim 300 \mathrm{~g} / \mathrm{kW}-\mathrm{h}$ in the case of the VDTCE, and this is expected to have a strong impact on vehicle fuel economy.

Figure 17 illustrates tremendous differences between engine operation in the conventional vehicle versus the powersplit HHV. In case of the conventional driveline, the engine speed is coupled directly to the vehicle speed, and there are frequent transients related to sudden changes of vehicle power demand or gear-shifts in the transmission. In contrast, the power-split system keeps the engine speed relatively low, with very mild variations. The differences are as pronounced in the middle plot, indicating huge and frequent fluctuations of engine torque in the conventional vehicle. In case of the PS-HHV the overall torque levels are comparable, but the high-frequency transients are completely eliminated and that bodes well for the engine with a turbocharger. The bottom plot shows the magnitude of the impact of very different engine operating characteristics and BSFC maps on the instantaneous fuel consumption. Integrating the areas under the curves in the bottom plot over the complete driving schedule enables determining the vehicle fuel economy shown in Table 4. The improvements with the VDTCE coupled to a power-split HHV system are remarkable for both the city and highway driving schedule. This is somewhat unexpected, as the hybrid system often delivers relatively higher benefits in city driving, due to ample chances for regeneration. The finding suggests that most of the benefits stem from the improvements of part load efficiency with the VDTCE concept, rather than hybridization.

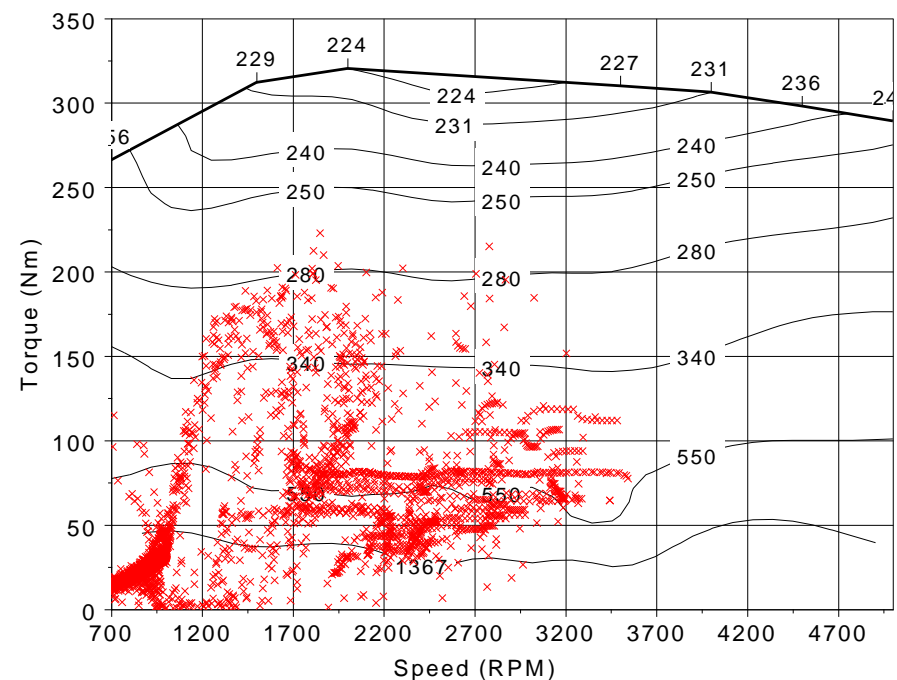

Figure 16: Operating points of a $3.6 \mathrm{~L}$ naturally aspirated engine in a conventional vehicle, simulated over an FTP75 driving cycle 

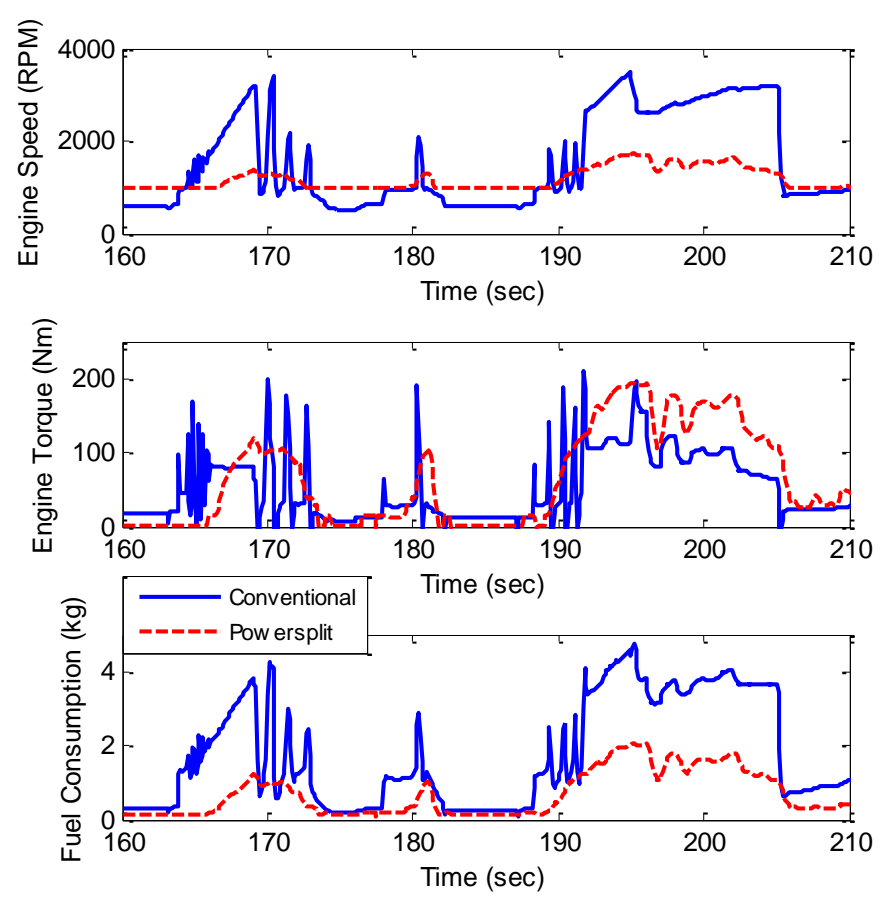

Figure 17: Conventional versus Power-split results over a segment of the FTP 75 driving schedule: engine speed (top), engine torque (middle), and fuel consumption (bottom).

Indeed, Figure 18 compares engine efficiencies over a driving cycle segment and shows that VDTCE's instantaneous efficiency is often more than two times greater than the corresponding values calculated for the conventional engine.

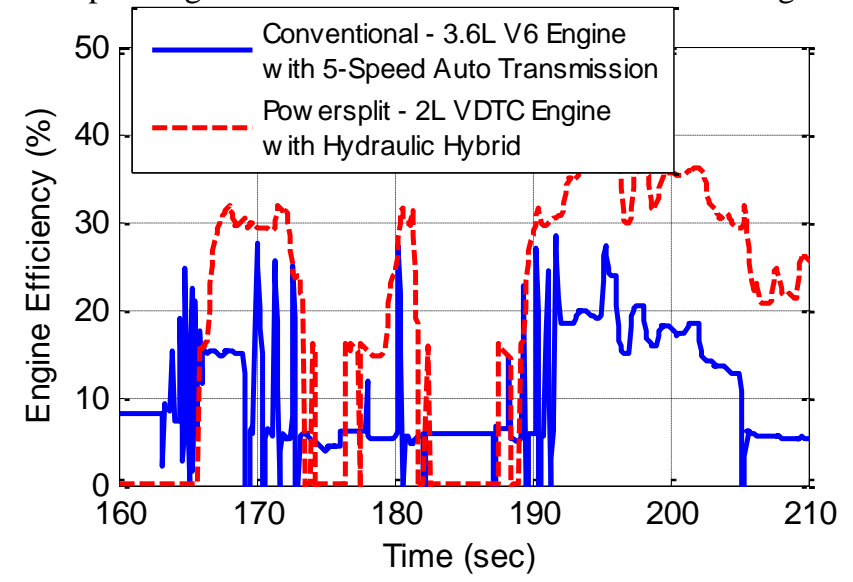

Figure 18: Instantaneous engine efficiency over a segment of the FTP75 driving cycle.

Table 4: Comparison of the drive cycle fuel economy: Conventional vs. the VDTCE Power-split Hybrid

\begin{tabular}{ccc}
\hline & $\begin{array}{c}\text { City (FTP75) } \\
(\mathrm{mpg})\end{array}$ & $\begin{array}{c}\text { Highway (HWFET) } \\
(\mathrm{mpg})\end{array}$ \\
\hline Conventional & 18.34 & 30.41 \\
VDTCE Power-split & 46.50 & 77.68 \\
\hline
\end{tabular}

In closing, the coupling of the VDTCE engine to a powersplit hydraulic hybrid provides exceptional benefits in terms of vehicle fuel economy. The analysis of interactions in the system suggest that most of the fuel economy improvements stem from exceptional part-load efficiency of the VDTCE, and the power-split hybrid system can be viewed as an enabler for the application of the VDTCE, since it keeps the engine operation within the feasible limits. The configurations analyzed in this study represent relatively high-performance vehicles, and both the conventional and the VDTCE engine are relatively oversized. Hence, the obtained results do not represent the ultimate fuel economy potential of the proposed powertrain concept, but rather demonstrate a fundamental transformation of the trade-off between vehicle performance and fuel economy. In addition, the relative contributions of the VDTCE efficiency and hybridization to total vehicle fuel economy improvements may change if the engine rated power is significantly decreased.

\section{CONCLUSION}

An advanced engine system design, combining variable displacement, cylinder deactivation and turbocharging has been explored with the aid of the physics-based computer simulation. The main objective was to develop a system capable of operating unthrottled throughout the torque-speed range. Regulating the load via reduced displacement and/or deactivating cylinders while keeping the throttle wide open produces very significant efficiency gains at low-load, but there is a limit below which the throttling would still be necessary. The nominal engine displacement is 2 liters, and the variable displacement mechanism allows reduction by a factor of two.

To avoid engine operation below the unthrottled load limit, facilitate smooth mode changes and further improve the vehicle fuel economy, the VDTCE engine is coupled to a power-split hydraulic hybrid driveline. The integration of the engine with the driveline and vehicle dynamics is carried out in SIMULINK, thus facilitating the development and implementation of the supervisory controller. Given the unique properties of the hydraulic components, very different than those typically seen in electric counterparts, a novel strategy was required. In particular, while the energy conversion and power density of components are comparatively high, the relatively low energy density of the hydraulic accumulator requires careful management of the State-Of-Charge. The modulated control maintains a relatively low desired SOC during normal operation in order to maximize the potential for regeneration, and concentrates engine operating points around the optimal BSFC trajectory to maximize efficiency and avoid regions unfeasible for the unthrottled operation.

The behavior of the PS-HHV powertrain with a VDTCE and its fuel economy potential are assessed through a comparison with the conventional baseline comprising a $3.6 \mathrm{~L}$ naturally aspirated engine mated to a five-speed automatic 
transmission. The engine operation in the PS-HHV is much smoother, without high-frequency fluctuations of torque, and at relatively low speeds. The average efficiency of the VDTCE over the transient schedule is more than twice that of the conventional baseline, hence most of the vehicle fuel economy improvement can be attributed to exceptional part-load efficiency of the VDTCE. The power-split hybrid system is the key enabler, given its ability to keep the engine in the desired speed/load area and avoid the unfeasible regions.

The advanced powertrain configuration investigated in this work is a high-performance option for the mid-size passenger vehicle. Therefore, while predicted fuel economy improvements are impressive, they do not represent the ultimate potential. Further downsizing of the engine and adjustments of the hybrid system design are possible if the performance constraints are relaxed. The further extension of the VDTCE study to include a realistic assessment of mechanical losses associated with the variable displacement mechanism and possible benefits of using a variable compression ratio is apparent.

\section{ACKNOWLEDGMENTS}

The authors would like to thank LMS for providing access the AMESim program, and opening up parts of the code to allow implementation of the original variable displacement model.

\section{REFERENCES}

1.J. Pierce, "Variable Stroke Mechanisms", U.S. Patent No. 1,112,832, October 6, 1914.

2.A. E. Biermann, "Variable Stroke Piston Engines", U.S. Patent No. 2,909,163, October 20, 1959.

3.H. W. Welsh, C. T. Riley, "The Variable Displacement Engine: An Advanced Concept Power Plant”, SAE Paper 710830, October 1971.

4.H. N. Pouliot, W. R. Delameter, C. W. Robinson, “A Variable Displacement Spark Ignition Engine”, SAE Paper 770114, February 1977.

5.V. W. Wong, M. Stewart, G. Lundholm, A. Hoglund, "Increased Power Density via Variable Compression/Displacement And Turbocharging using the Alvar-Cycle Engine”, SAE Paper 981027, February 23-26, 1998.

6.D. C. Siegla, R. M. Siewert, "The Variable Stroke Engine Problems and Promises," SAE Paper 780700, August 1978.

7.R. M. Siewert, "Engine Combustion at Large Bore-to-Stroke Ratios," SAE Paper 780968, 1978.
8.M. Alsterfalk, Z. Filipi, D. Assanis, "The Potential of the Variable Stroke Spark-Ignition Engine", SAE Paper 970067, February 24-27, 1997.

9.K. Muta, M. Yamazaki, J. Tokieda, "Development of NewGeneration Hybrid System THS II - Drastic Improvement of Power Performance and Fuel Economy", SAE paper 2004-01-0064, 2004.

10.J. Alson, D. Barba, J. Bryson, M. Doorag, D. Haugen, J. Kargul, J. McDonald, K. Newman, L. Platte, M. Wolcott 'Progress Report on clean and Efficient Automotive Technologies under Development at EPA', EPA420-R-04002, United States Environmental Protection Agency, 2004.

11.Z. Filipi, L. Louca, B. Daran, C.-C. Lin, B. Wu, M. Kokkolaras, D. Assanis, H. Peng, P. Papalambros, J. Stein, D. Szkubiel, R. Chapp, "Combined Optimization of Design and Power Management of the Hydraulic Hybrid Propulsion System for the 6x6 Medium Truck", Int. J. Heavy Vehicle Systems, Vol. 11, pp. 371-401, 2004.

12.B. Wu, C.-C. Lin, Z. Filipi, H. Peng, D. Assanis, "Optimal Power Management for a Hydraulic Hybrid Delivery Truck”, Int. J. Vehicle System Dynamics, Vol. 42, Nos 1-2, pp. 23-40, 2004.

13.Y. J. Kim, Z. Filipi, "Simulation Study of a Series Hydraulic Hybrid Propulsion System for a Light Truck", SAE paper 2007-01-4151, 2008 SAE Transactions, Journal of Commercial Vehicles, also presented at the 2007 SAE Commercial Vehicle Engineering Congress \& Exhibition, Chicago, October 2007.

14.M. Duoba, H. Lohse-Busch, R. Carlson, T. P. Bohn, S. Gurski, "Analysis of Power-Split HEV Control Strategies Using Data from Several Vehicles", SAE paper 2007-010291, 2007.

15.Hefley Engine Concept, http://www.hefleyengine.com

16.AMESim Rev 7A ENGCFM02 Combustion Model, "CFM $1 \mathrm{D}$ model for combustion heat release + fuel evaporation [liquid injection]", 2007.

17.M. Metghalchi, J. C. Keck, "Burning Velocities of Mixtures of Air with Methanol, Isooctane and Indolence at High Pressure and Temperature", Combust and Flame 48, 191210, 1982.

18.F. A. Lafossas, O. Colin, F. Le Berr, P. Menegazzi, "Application of a New 1D Combustion Model to Gasoline Transient Engine Operation”, SAE, 2005-01-2107, 2005. 
19.F. A. Lafossas, M. Castagne, J. P. Dumas, S. Henroit, "Development and validation of a knock model in spark ignition engines using a CFD code", SAE, 2002-01-2701, 2002.

20.AMESim 7A ENGCOMP00, "Compressor model with inertia", 2007.

21.AMESim 7A ENGTURBSS01, "Single scroll turbine (tables reading + back flow)", 2007.

22.L. M. Mladenovic, "Mass Air Flow Rate per Cylinder Estimation without Volumetric Efficiency Map", GM, U.S. Patent No. 7139656, November 21, 2006.

23.A. Pourmovahed, N. H. Beachley, F. J. Fronczak, "Modeling of a Hydraulic Energy Regeneration System", ASME Journal of Dynamic Systems, Measurements and Controls, Vol 114, pp 155- 159, March 1992.

24.D.R. Otis, A Pourmovahed, "An Algorithm for Computing Nonflow Gas Processes in Gas Springs and Hydropneumatic Accumulators", ASME Journal of Dynamic Systems, Measurements and Controls, Vol 107, No. 1, pp 93-96, 1985.

25."Thermophysical Properties of Nitrogen from the Fusion Line to $3500 \mathrm{R}(1944 \mathrm{~K})$ for Pressures to 150,000 Psia (1.0342 GPa)", NBS Technical Note 648, December 1973.

26.Z. Filipi, Y. J. Kim, "Hydraulic Hybrid Propulsion for Heavy Vehicles: Combining the Simulation and Engine-in-theLoop Techniques to Maximize the Fuel Economy and Emission Benefits" Proceedings of the International Conference on Advances in Hybrid Powertrains, IFP, Paris, France, Nov. 25-26, 2008.

\section{NOMENCLATURE}

\section{Fuel Controller}

\begin{tabular}{ll}
\hline$\dot{m}_{f b}$ & Mass air flow rate due to feedback \\
$K_{p, f b}$ & Proportional gain of feedback \\
$K_{i, f b}$ & Integral gain of feedback \\
$\lambda$ & Air to fuel equivalence ratio \\
$\lambda_{d e s}$ & Desired air to fuel equivalence ratio \\
$L$ & Stroke length \\
$d_{p}$ & Piston diameter \\
$\dot{m}_{t}$ & Mass air flow rate through throttle \\
$\dot{m}_{f f}$ & Mass air flow rate from feedforward \\
$R$ & Ideal gas constant \\
$T$ & Intake manifold temperature
\end{tabular}

\begin{tabular}{ll}
\hline$P_{e}$ & Intake manifold estimated pressure \\
$P_{a}$ & Intake manifold measured pressure \\
$K_{p, f f}$ & Proportional gain of feedforward \\
$K_{i, f f}$ & Integral gain of feedforward \\
$A F R$ & Air to fuel ratio \\
$\dot{f}$ & Fueling rate \\
$\theta_{i d}$ & Crank angle injection duration \\
$\omega$ & Engine speed \\
$t_{i n j}$ & Injection duration \\
$S F R$ & Static fueling rate \\
\hline
\end{tabular}

THS System

$\begin{array}{ll}R & \text { Ring gear radius } \\ S & \text { Sun gear radius } \\ T_{p} & \text { Pump torque } \\ T_{c} & \text { Carrier gear torque } \\ T_{r} & \text { Ring gear torque } \\ I_{e} & \text { Engine inertia } \\ T_{e} & \text { Engine torque } \\ \omega_{c} & \text { Carrier gear speed } \\ \omega_{e} & \text { Engine speed } \\ v & \text { Vehicle velocity } \\ R_{t i r e} & \text { Tire radius } \\ F R & \text { Final drive ratio } \\ \omega_{r} & \text { Ring gear speed } \\ S R & \text { Speed reducer ratio } \\ \omega_{s} & \text { Sun gear speed } \\ \omega_{p} & \text { Pump speed }\end{array}$

\section{Driver}

\begin{tabular}{ll}
$K_{p, d r}$ & Driver proportional gain \\
$K_{i, d r}$ & Driver integral gain \\
$v_{d e s}$ & Desired vehicle speed \\
$v_{a c t}$ & Actual vehicle speed \\
\hline
\end{tabular}

\section{Vehicle}

\begin{tabular}{ll}
$f$ & Rolling friction coefficient \\
$m$ & Vehicle mass \\
$g$ & Gravitational acceleration \\
$R_{\text {tire }}$ & Tire radius \\
$T_{\text {rolles }}$ & Rolling resistance torque \\
$A_{f}$ & Vehicle frontal area \\
$C_{d}$ & Vehicle coefficient of drag \\
$\rho$ & Air density \\
$\omega_{w}$ & Vehicle wheel speed \\
\hline
\end{tabular}




\begin{tabular}{ll}
\hline$T_{\text {drag }}$ & Vehicle drag torque \\
$R_{\text {vis }}$ & Vehicle viscous friction coefficient \\
$F_{\text {stat }}$ & Vehicle static friction \\
$x_{\text {brake }}$ & Driver brake command \\
$\omega_{\text {min }}$ & Minimum vehicle speed \\
$T_{\text {brake }}$ & Vehicle brake torque \\
$T_{\text {drive }}$ & Driveshaft torque \\
$v$ & Vehicle speed \\
\hline
\end{tabular}

\begin{tabular}{ll} 
Accumulator & \\
\hline$R$ & Ideal gas constant \\
$T$ & Nitrogen gas temperature \\
$A_{0}, B_{0}, C_{0}, a, b, C, \alpha, \gamma$ & Benedict Webb Rubbin constants \\
$v$ & Nitrogen gas specific volume \\
$p_{g}$ & Nitrogen gas pressure \\
$m_{f}$ & Mass of Foam \\
$m_{g}$ & Mass of gas \\
$c_{f}$ & Specific heat of foam \\
$A_{w}$ & Effective accumulator wall area \\
$h$ & Heat transfer coefficient \\
$c_{v}$ & Constant-volume gas specific heat \\
\hline
\end{tabular}

\begin{tabular}{ll} 
Pump/Motor & \\
\hline$C_{s}$ & Laminar leakage coefficient \\
$C_{s t}$ & Turbulent leakage coefficient \\
$x$ & Pump command \\
$S, \sigma$ & Dimensionless coefficients \\
$\beta$ & Hydraulic fluid bulk modulus \\
$Q_{a}$ & Actual pump flow rate \\
$Q_{i}$ & Ideal pump flow rate \\
$\eta_{v, \text { pump }}$ & Pump volumetric efficiency \\
$C_{v}$ & Viscous loss coefficient \\
$C_{f}$ & Frictional loss coefficient \\
$C_{h}$ & Hydrodynamic loss coefficient \\
$T_{a}$ & Actual torque \\
$T_{i}$ & Ideal torque \\
$\eta_{t, \text { pump }}$ & Pump torque efficiency \\
\hline
\end{tabular}

\section{Supervisory Control}

\begin{tabular}{ll}
\hline$K_{p}$ & Supervisory control proportional gain \\
$K_{i}$ & Supervisory control integral gain \\
SOC $_{d e m}$ & Demanded state of charge \\
SOC & Current state of charge \\
$P_{e, d}$ & Engine power demand \\
\hline
\end{tabular}

